\title{
A simplified categorization for common arterial trunk
}

\author{
Hyde M. Russell, MD, ${ }^{a}$ Marshall L. Jacobs, MD, ${ }^{b}$ Robert H. Anderson, MD, ${ }^{c}$ Constantine Mavroudis, MD, ${ }^{b}$ \\ Diane Spicer, PA, ${ }^{\mathrm{d}}$ Eowyn Corcrain, $\mathrm{MSc},{ }^{\mathrm{e}}$ and Carl L. Backer, $\mathrm{MD}^{\mathrm{a}}$
}

\begin{abstract}
Objective: A common arterial trunk is a solitary trunk that exits the heart through a common ventriculo-arterial junction and supplies directly the systemic, pulmonary, and coronary arterial pathways. It remains to be determined, however, how best to subclassify those hearts fulfilling this definition. The time-honored classification is based on the morphology of the pulmonary arteries, but an alternative approach also places emphasis on the nature of the systemic pathways. We evaluated our experience to establish whether these different approaches can be reconciled.
\end{abstract}

\begin{abstract}
Methods: We examined 28 autopsied hearts with common arterial trunks; the specimens were drawn from the archives of three institutions. Based on our analysis, we simplified classification into hearts with aortic or pulmonary dominance. We used this approach to categorize 42 patients who had undergone surgical correction at Children's Memorial Hospital in Chicago.
\end{abstract}
Results: All autopsied hearts could be assigned to groups with either aortic or pulmonary dominance of the com- mon arterial trunk, with 20 and 8 specimens, respectively, fitting into these categories. Pulmonary dominance was found only when the aortic component of the trunk was hypoplastic and an arterial duct supplied the ma- jority of flow to the descending aorta. Only in this setting did we observe pulmonary arteries arising from the sides of the major pathway, and only in this setting was the aortic component discrete from the pulmonary com- ponent within the pericardial cavity.

Conclusions: This simple approach to classification reconciles the existing disparate categorizations of patients having common arterial trunks and it emphasizes the principal morphologic determinant of surgical outcome. (J Thorac Cardiovasc Surg 2011;141:645-53)

Hearts with a common arterial trunk belong to a family of congenital cardiac malformations that has stimulated considerable critical thinking and controversy among surgeons and anatomists alike in regard to its most appropriate description and classification. The original scheme for classification, set forth by Collett and Edwards in 1949, ${ }^{1}$ still enjoys widespread support. This system was used by the Congenital Heart Surgeons' Society (CHSS) in its collaborative study of patients with common arterial trunk and interruption of the aortic arch. ${ }^{2}$ In a commentary that accompanied that publication, ${ }^{3}$ it was pointed out that many surgeons preferred to use the system of classification proposed by Van Praagh in $1965,{ }^{4}$ which recognizes patients with interruption of the aortic arch as a specific subset within the category of com-

\footnotetext{
From Division of Cardiovascular-Thoracic Surgery, ${ }^{\text {a }}$ Children's Memorial Hospital, Chicago, Ill; Department of Pediatric and Congenital Heart Surgery, ${ }^{\mathrm{b}}$ Cleveland Clinic, Cleveland, Ohio; Division of Pediatric Cardiology ${ }^{\mathrm{c}}$ and Department of Pathology, ${ }^{\mathrm{e}}$ Medical University of South Carolina, Charleston, SC; Division of Pediatric Cardiology, ${ }^{\mathrm{d}}$ University of Florida, Gainesville, Fla; and Congenital Heart Institute of Florida, St. Petersburg, Fla.

Disclosures: Authors have nothing to disclose with regard to commercial support. Received for publication March 22, 2010; revisions received July 9, 2010; accepted for publication Aug 1, 2010; available ahead of print Oct 21, 2010

Address for reprints: Hyde Russell, MD, Division of Cardiovascular-Thoracic Surgery, Children's Memorial Hospital, 2300 Children's Plaza, mc 22, Chicago, IL 60614 (E-mail: hrussell@childrensmemorial.org).

$0022-5223 / \$ 36.00$

Copyright (C) 2011 by The American Association for Thoracic Surgery doi:10.1016/j.jtcvs.2010.08.022
}

mon arterial trunk. Further analysis of the CHSS study, ${ }^{2}$ revealed a potential problem with the use of either of the two existing popular systems for categorization. ${ }^{1,4}$ As was shown by Van Praagh ${ }^{4}$ and endorsed by Calder, ${ }^{5}$ the essence of the problem in hearts that have interruption of the aortic arch is that the main component of the common arterial trunk is continued via the arterial duct to the descending aorta, with the pulmonary arteries arising from either side of the main pathway for the pulmonary circulation. Such patients, therefore, not only qualify for categorization within the first subset of the system proposed by Collett and Edwards ${ }^{1}$ because they show evidence of extensive formation of distinct intrapericardial pulmonary and aortic pathways, but they also qualify for categorization within the third subtype on the basis of the mode of origin of the branch pulmonary arteries. Although all cases with interrupted aortic arches studied by Van Praagh ${ }^{4,5}$ were described as having a discrete intrapericardial pulmonary arterial segment, only half of the patients collected in the CHSS collaborative study were categorized as having such type 1 anatomy, and only a small proportion were considered to have type 3 morphology. ${ }^{2}$ In an attempt to resolve this paradox, we have revisited the categorization of common arterial trunk.

We believe that schemes for classification should perform at least two functions. First, they should provide a common language so all clinicians can easily recognize the lesion in question and be able to identify its subcategories. 


\section{Abbreviation and Acronym \\ CHSS $=$ Congenital Heart Surgeons' Society}

Second, the categorizations should provide the basis for identification of meaningful differences in the natural history and surgical approaches when considering stratification of risk. Our review of the pathologic specimens at our disposal served to reinforce the advantages of such a simplified scheme ${ }^{6}$ based on the dominance of either the systemic or pulmonary components of the common trunk. We then sought to apply this categorization retrospectively to the patients who underwent surgical correction at Children's Memorial Hospital, assessing the value of the simplified scheme relative to outcomes.

\section{MATERIALS AND METHODS}

We examined all specimens identified as having common arterial trunk in the Idriss Archive at Children's Memorial Hospital, the Van Mierop Archive of the University of Florida in Gainesville, and the archive of autopsied hearts held at Medical University of South Carolina in Charleston. We defined the lesion on the basis of a solitary arterial channel exiting from the base of the heart via a common ventriculo-arterial valve and supplying directly part or all of the systemic, pulmonary, and coronary arterial systems. ${ }^{1,4,5,7}$ We paid particular attention to the relative size of the components of the intrapericardial arterial pathways, the mode of origin of the right and left pulmonary arteries, the site of the coronary arterial orifices relative to the truncal root, and the number of leaflets within the valve guarding the common ventriculo-arterial junction. We also noted the sidedness of the aortic arch, the presence or absence of aortic interruption or coarctation, the morphology of the interventricular communication, the commitment of the common ventriculo-arterial junction relative to the morphologically right and left ventricles, and the presence or absence of an arterial duct or corresponding ligament.

We then accessed the cardiac surgical database of Children's Memorial Hospital, Chicago, identifying all patients with common arterial trunk who underwent surgical repair. We identified all relevant aspects of anatomy described by the surgeons and obtained follow-up data from outpatient visits, echocardiographic evaluations, and admissions for reoperations.

Statistical analysis was performed using the Pearson chi-square test for nominal variables where appropriate. This study was approved by the institutional review board at Children's Memorial Hospital, Chicago.

\section{DEFINITIONS}

There is general agreement on the criteria for diagnosis suggested by Collett and Edwards. ${ }^{1}$ First, there should be one arterial trunk exiting the base of the heart, in the absence of any atretic remnant of the aorta or pulmonary trunk; and second, the solitary trunk should supply branches directly to the coronary, pulmonary, and systemic circulations. The essence of the Collett and Edwards ${ }^{1}$ categories relative to the current study is that type 1 is characterized by "a single pulmonary trunk and ascending aorta arise from the truncus arteriosus." 1 The feature of the type 2 was that "the right and left pulmonary arteries arise close together from the dorsal wall of the truncus arteriosus." ${ }^{1}$ They defined type 3 as the situation in which "one or both pulmonary arteries arise independently from either side of the truncus arteriosus."1 When using these definitions to categorize our material,
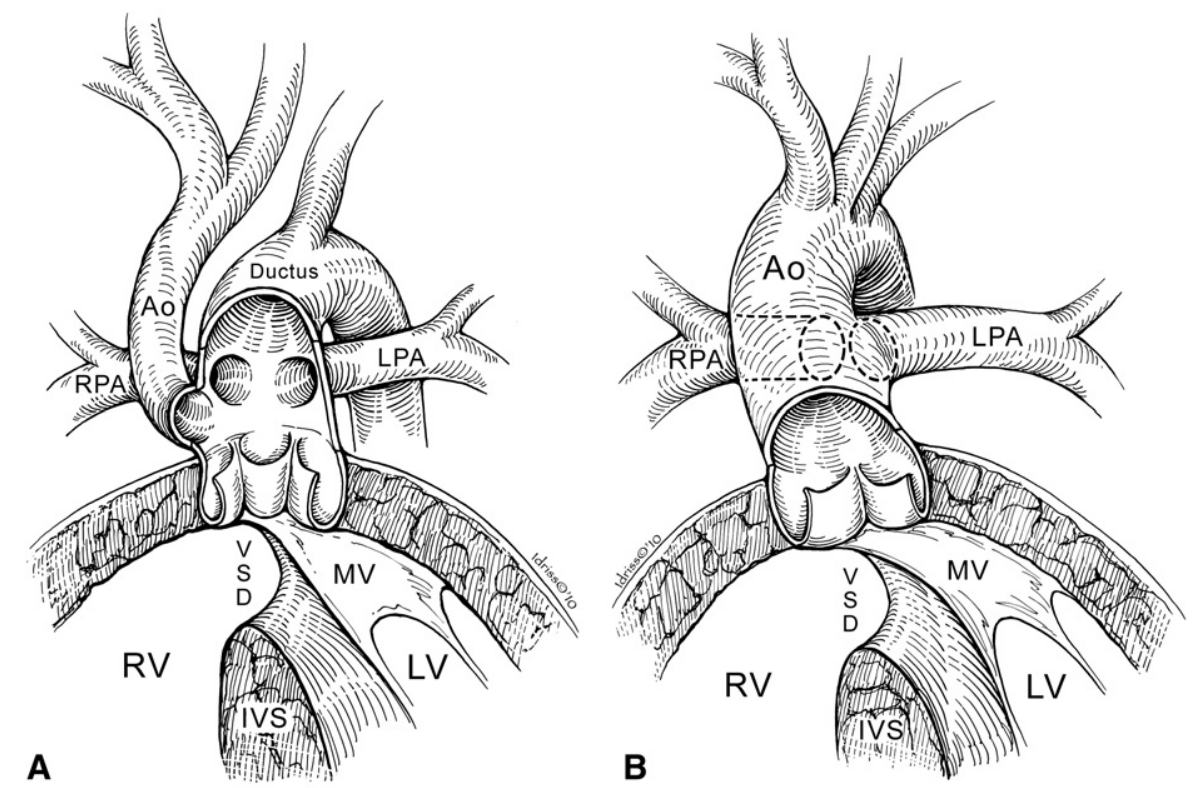

FIGURE 1. The cartoon shows the essential features of pulmonary versus aortic dominance as observed in our autopsied specimens with common arterial trunk. Panel A shows interruption of the aortic arch. Only in this setting, and in hearts with severe aortic coarctation, did we find origin of the pulmonary arteries from either side of the intrapericardial pulmonary trunk. Panel B shows the salient features of aortic dominance, with the pulmonary arteries arising separately but next to each other from the leftward and dorsal aspect of the common trunk. We also found pulmonary arteries arising more anteriorly, and then crossing as they extended toward the pulmonary hilums. 

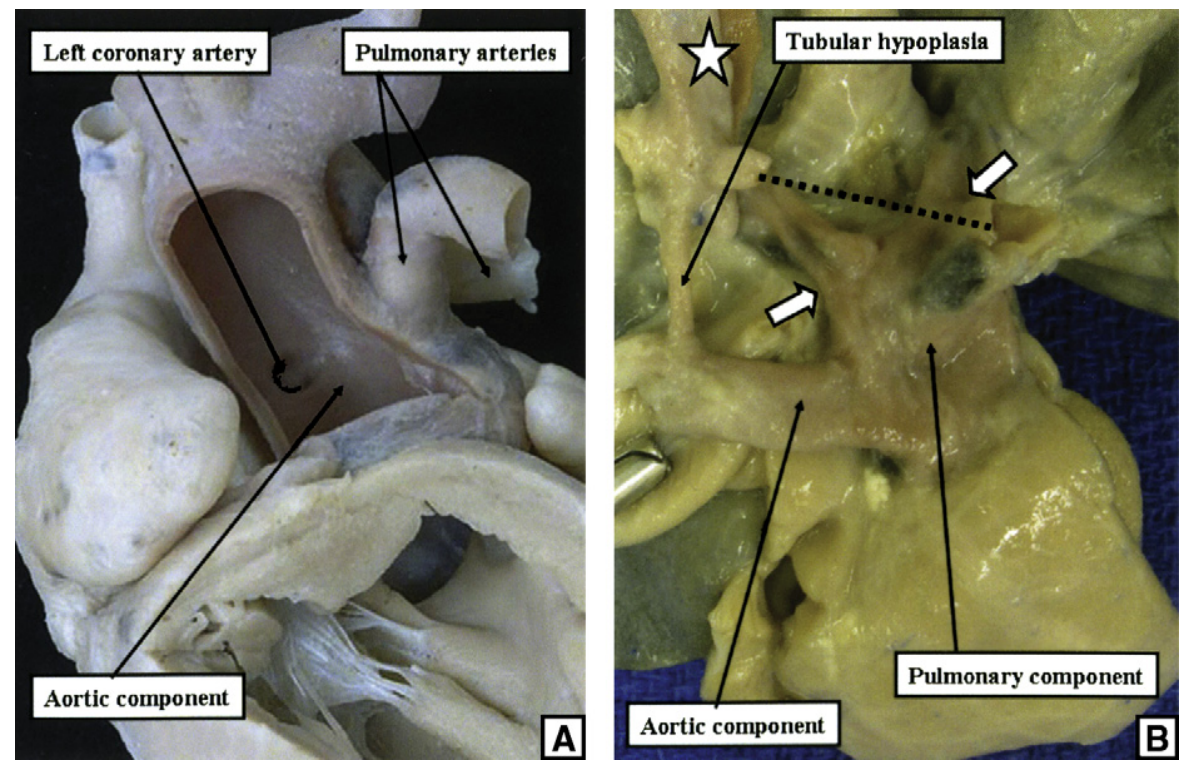

FIGURE 2. The illustrations show the pattern of aortic (A) as opposed to pulmonary (B) dominance of the coronary arterial trunk. In the heart shown in A, the pulmonary arteries arise from the anterior and leftward component of the trunk and cross one another as they extend to the pulmonary hilums. This is the arrangement known as crossed pulmonary arteries (see Figure 3). The heart shown in B has severe hypoplasia of the transverse aortic arch. The arterial duct initially connected with the descending aorta (star). It was divided during prosection of the specimen, but its course is shown by the dotted line. The hypoplastic aorta has been turned away to show the origins of the right and left pulmonary arteries from the side of the dominant pulmonary component of the common trunk.

we found that only those patients with either aortic interruption or severe coarctation showed presence of a discrete pulmonary trunk within the pericardial cavity, and it was always in the setting of a hypoplastic intrapericardial aorta. We therefore characterized these patients as being pulmonary dominant (Figure 1, $A$ ). In all the other patients, in whom the common trunk itself continued to supply the brachiocephalic arteries, the pulmonary arteries arose close together from the dorsal wall of the trunk. We characterized these patients as aortic dominant (Figure 1, $B$ ). The rarely reported observation of equally sized aortic and pulmonary components of the common trunk justifies the consideration

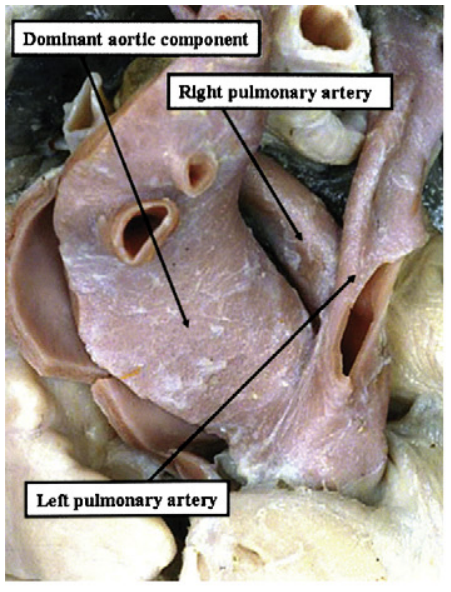

A

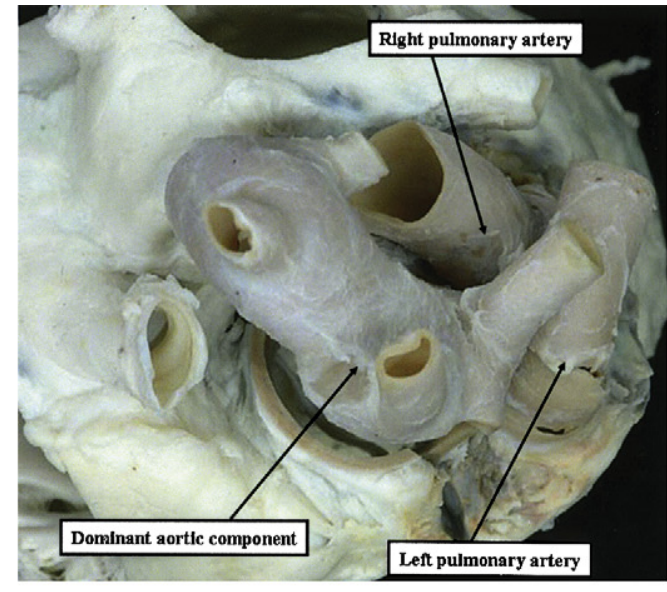

B

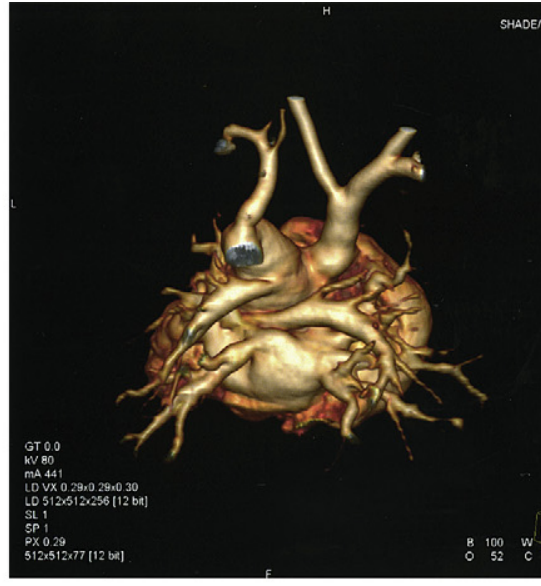

C

FIGURE 3. Some hearts with common arterial trunk show the pattern of origin known as crossed pulmonary arteries. In the left panel (A), the image of a heart with aortic dominance, it can be seen that the left pulmonary artery arises anteriorly from the left side of the aortic component of the trunk and spirals around the more posterior origin of the right pulmonary artery. The heart shown in A is photographed from the front; the heart shown in the middle panel (B), again with aortic dominance, is photographed from above. In the latter heart, the pulmonary arteries arose in part within the truncal valvar sinuses (see Figure 5). In the heart shown in the right panel (C), with the morphology revealed by computed tomography as seen posteriorly, there is pulmonary dominance but with obvious crossed origin of the right and left pulmonary arteries. 


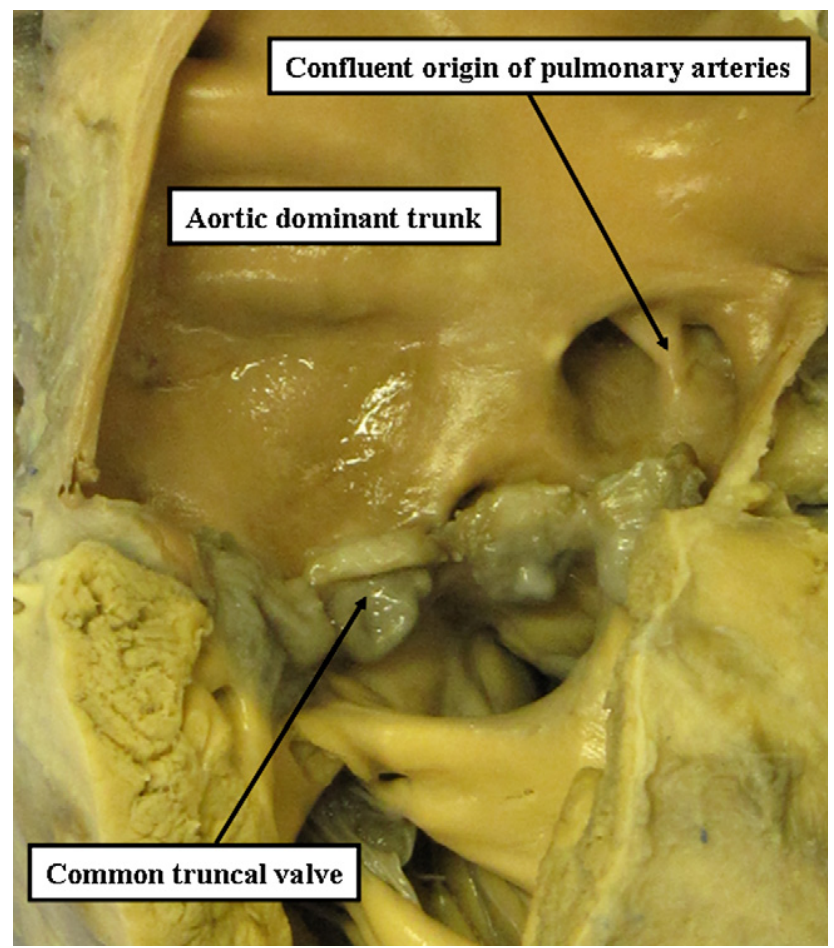

FIGURE 4. The common arterial trunk has been opened to show the more usual pattern of origin of the pulmonary arteries in the setting of aortic dominance. The right and left pulmonary arteries take a confluent origin from the left and posterior aspect of the common trunk.

of a third category, that being common arterial trunk with a balanced common trunk.

\section{RESULTS \\ Anatomic Study}

We identified 17 specimens in the Idriss archive, 7 specimens in the Van Mierop archive, and 4 in the archive of the Medical University of South Carolina. Of these 28 hearts, 20 displayed dominance of the aortic component of the common arterial trunk (Figure 2, A), and 8 showed dominance of the pulmonary component, the intrapericardial aorta being significantly hypoplastic (Figure 2,B). Of those with aortic dominance, none had an obviously discrete intrapericardial pulmonary trunk. The structure we observed that was closest to this morphology was seen in 4 hearts in which the pulmonary arteries, although separate from one another, crossed as they took origin from the anterior and leftward margin of the common arterial trunk (Figure 3). In the remaining 16 specimens with an aortic dominant common trunk, the right and left pulmonary arteries arose separately but adjacent to one another at the leftward and posterior margin of the trunk, with no obvious presence of a discrete intrapericardial pulmonary arterial segment (Figure 4). In 2 hearts, including one with crossed pulmonary arteries (Figure 3, $B$ ), the origins of the right and

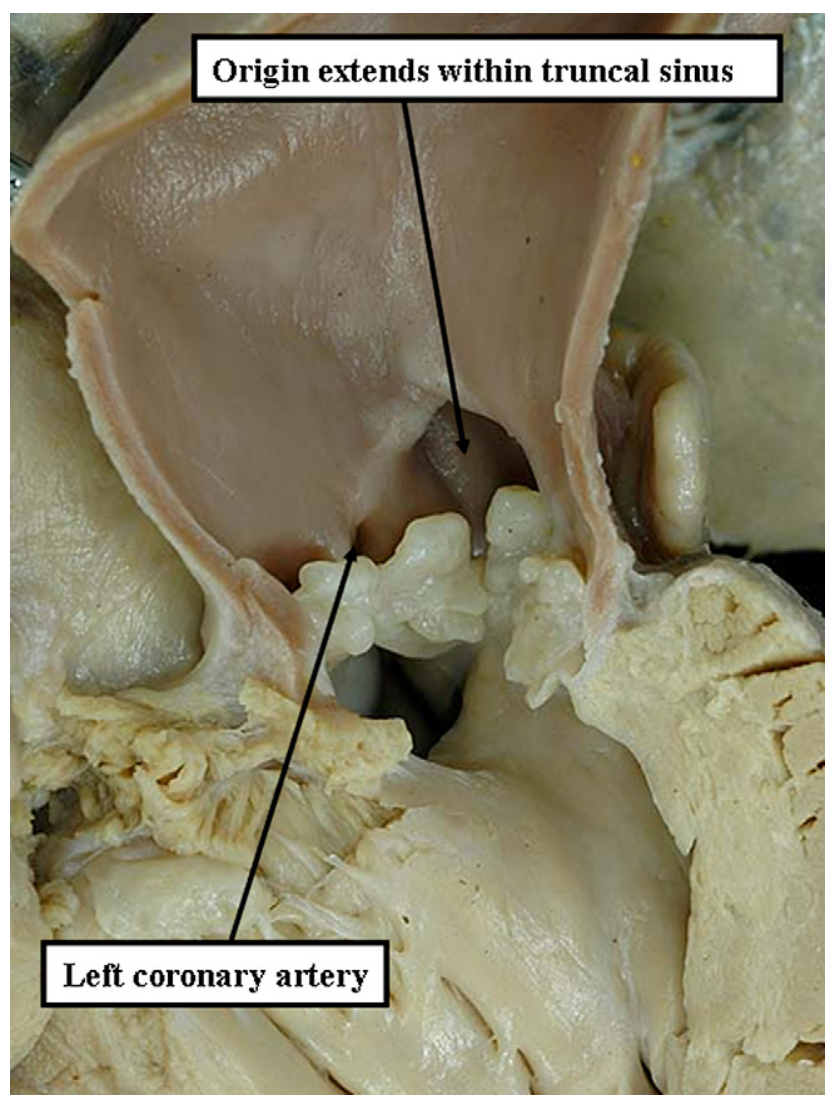

FIGURE 5. As in the heart shown in Figure 4, which has aortic dominance, the right and left pulmonary arteries in this specimen take a confluent origin from the leftward and posterior margin of the trunk, but in this instance the origin is partly within a truncal valvar sinus.

left pulmonary arteries were partially within a truncal valvar sinus (Figure 5). We found no hearts with a balanced common trunk in any of these archives.

Of the 8 specimens with pulmonary arterial dominance, 6 had interruption of the aortic arch between the left carotid and left subclavian arteries, so-called type B interruption, whereas 1 had severe aortic coarctation. The arch was not available for evaluation in the remaining specimen. In 7 of these 8 hearts with pulmonary dominance, all having a discrete but significantly hypoplastic intrapericardial aorta, the right and left pulmonary arteries arose at a distance from each other, originating from either side of the dominant pulmonary component of the common trunk and exiting from the trunk at the margins of the pericardial cavity (Figure 6, $A$ ). In the final heart with pulmonary dominance, the pulmonary arteries took their origin from the posterior margin of the pulmonary component, and there was a significant separation of their orifices, but with the left pulmonary artery originating rightward and then spiraling across the origin of the right pulmonary artery; this arrangement was comparable to the situation of crossing pulmonary arteries seen in the setting of aortic dominance 


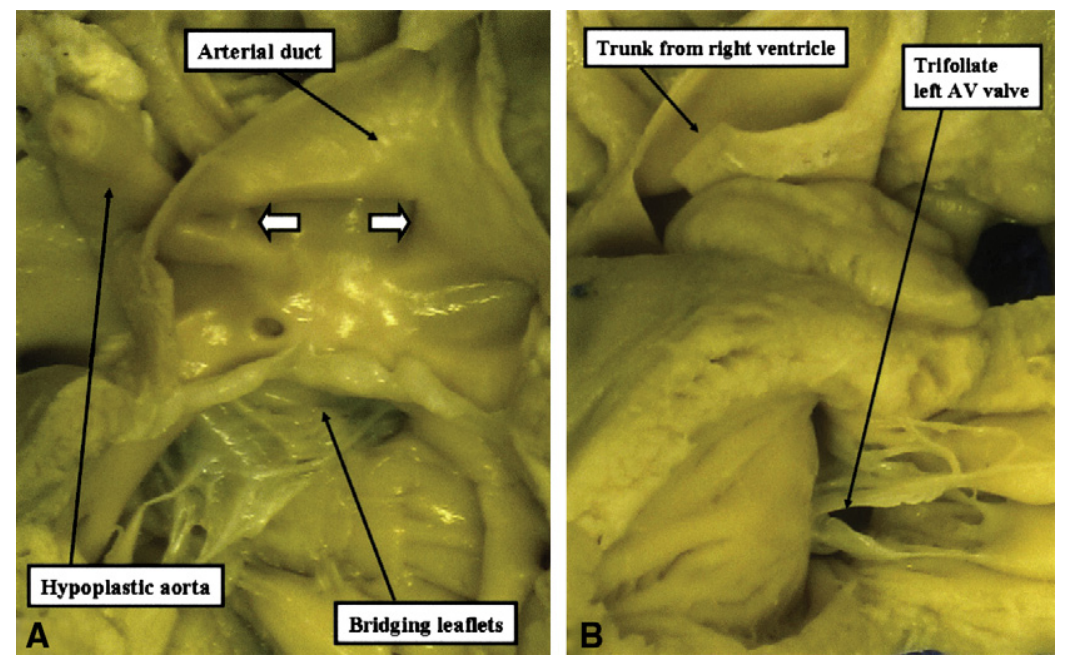

FIGURE 6. In this heart, the common arterial trunk arises exclusively from the morphologic right ventricle, as seen in panel A, and continues via the arterial duct to supply the descending aorta. The aortic arch is interrupted between the origins of the left common carotid and left subclavian arteries, and the ascending component is grossly hypoplastic. Note that the right and left pulmonary arteries (arrows) arise from the sides of the dominant pulmonary component of the trunk. Note also the presence of a common atrioventricular valve, with the typical trifoliate arrangement of the part of the valve committed to the left ventricle (panel B).

(Figure 3). In 2 of the hearts with pulmonary dominance, there was also a common atrioventricular junction guarded by a common atrioventricular valve. In these hearts the common arterial trunk arose exclusively from the morphologically right ventricle (Figure 6).

In 17 of the hearts, the truncal valve was trifoliate; 10 hearts exhibited a quadrifoliate valve; and 1 had a bifoliate valve. The pattern of origin of the coronary arteries was comparable in the majority of the hearts, with the right coronary artery originating anteriorly from the truncal root, and the main stem of the left coronary artery taking its origin from the left posterior aspect of the root, albeit well distal to the sinotubular junction in some instances (Figure 2, A). In 4 hearts, both coronary arteries originated from posterior truncal sinuses, whereas in 1 heart there was a single coronary artery. In 19 hearts, the postero-inferior rim of the interventricular communication was muscular (Figure 7, $A$ ), and in the other 9 hearts the defect extended to become confluent with an area of fibrous continuity between the leaflets of the truncal and tricuspid valves (Figure 7, $B$ ) or the superior bridging leaflet of the common atrioventricular valve in the hearts with common atrioventricular junction. Statistical analysis failed to demonstrate any significant association between any of these variables and aortic as opposed to pulmonary dominance of the common trunk.

\section{Clinical Study}

We were able to identify 42 children with common arterial trunk who had undergone surgical repair at Children's Memorial Hospital over the period of 30 years extending from 1979 to 2009 . The age at repair ranged from 1 week to 5 years, with a median of 14 days. The surgical descrip- tions were adequate for categorization of the lesion but did not specify details regarding the morphologic borders of the interventricular communication. The degree of override of the truncal valve and the number of valvar leaflets also were not described with sufficient consistency to allow for meaningful comparisons. There were 38 patients with dominance of the aortic component of the arterial trunk and 4 patients with pulmonary dominance. In 1 of the patients with pulmonary dominance, the pulmonary arteries arose from the side of the arterial trunk but with obvious crossing of the right and left pulmonary arteries (Figure 3,C).

There were 12 interventions in the truncal valve for truncal insufficiency in the group of 38 patients with aortic dominance. In 4 patients, it was necessary to replace the truncal valve; repair was required in 8 patients. There were no interventions on the truncal valve in the 4 patients with pulmonary dominance. Follow-up was available for 40 of these patients $(97 \%)$, with the mean period of follow-up being 8.1 years. Of the patients, 39 had survived to leave the hospital $(95 \%)$, and 36 remained alive at the latest follow-up $(88 \%)$. Only 1 patient with aortic dominance underwent cardiac transplantation; it was performed 21 years after the initial repair. The survival rate was $66 \%$ in the patients with pulmonary dominance, compared to $84 \%$ in those having aortic dominance.

\section{DISCUSSION}

Debate continues about how best to classify hearts with common arterial trunk, or persistent truncus arteriosus. ${ }^{3}$ There is general agreement, however, ${ }^{4,5,7}$ that the defining phenotypic feature of the lesion is the solitary nature of the arterial trunk exiting the heart through a common 

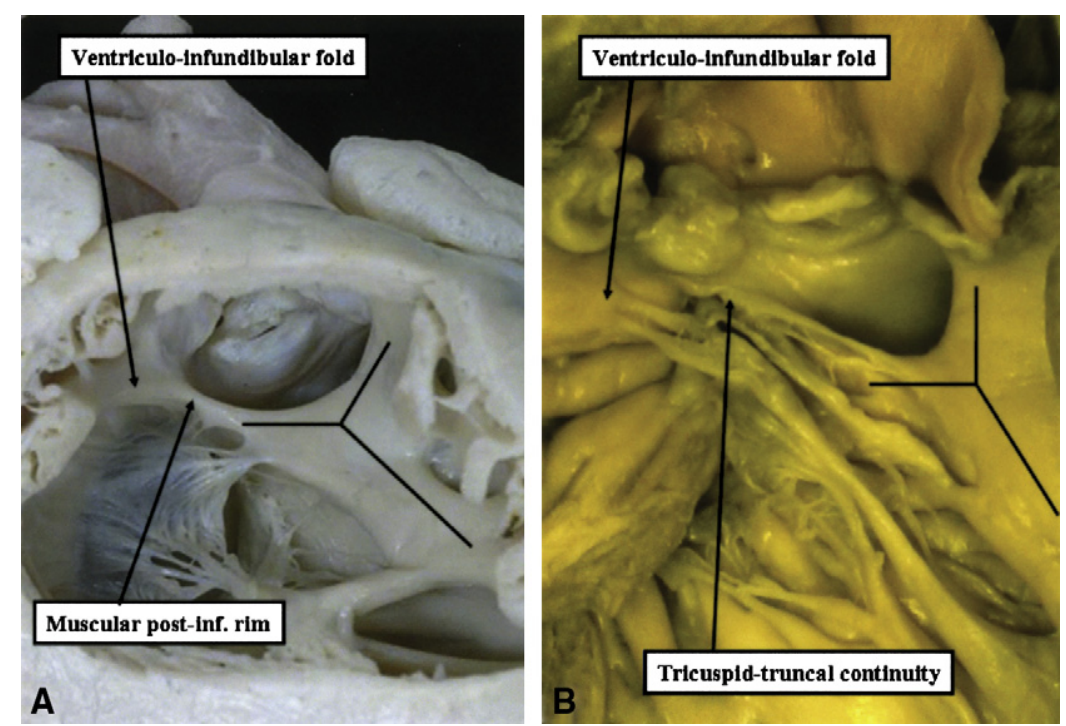

FIGURE 7. The illustrations show how variability in the relationships of the inner heart curvature, or ventriculo-infundibular fold, and the caudal limb of the septomarginal trabeculation, or septal band (black $Y$ ) determine the morphologic nature of the postero-inferior margin of the interventricular communication. In the majority of instances (panel A), these structures fuse to produce a postero-inferior muscular bar that protects the atrioventricular conduction axis. In the minority of cases (panel B), there is fibrous continuity between the leaflets of the truncal and tricuspid valves, making the defect perimembranous and putting the atrioventricular conduction axis at greater potential for surgical risk.

ventriculo-arterial junction guarded by a common arterial valve, the trunk then supplying directly the aortic, pulmonary, and coronary circulations, as originally proposed by Collett and Edwards. ${ }^{1}$ These initial investigators then suggested a subclassification based on the presumed embryologic development of the pulmonary arteries from the sixth aortic arches. ${ }^{1}$ In this respect, their analysis of previously published cases revealed marked variation in the origin of the pulmonary arteries among those grouped together because of the presence of a discrete intrapericardial pulmonary trunk. This fact, however, produces a paradoxical situation in which the patients falling most obviously within the type 1 pattern identified by Collett and Edwards ${ }^{1}$ also exhibit the so-called type 3 arrangement. In addition, none of the autopsied hearts with aortic dominance that we examined possessed the archetypical morphology of a distinct intrapericardial pulmonary trunk as depicted by Collett and Edwards ${ }^{1}$ in their simplified diagram (their Figure 463a; reproduced in our Figure 8, upper left). The most common arrangement we found in hearts with aortic dominance was the arrangement depicted as Collet-Edwards type 2 (their figure 463b; reproduced in our Figure 8, upper right). And the scheme they drew to represent their type 3 arrangement (Figure 8, lower left) bears no resemblance to the hearts we were able to identify in which the pulmonary arteries arose from the sides of the pulmonary component. It is interesting that the arrangement of pulmonary-dominant common arterial trunk that we found had been depicted by Collett and Edwards as a variant of type 1 anatomy (their Figure 464e; reproduced in our Figure 8, lower right). Thus, the scheme proposed by Collett and Edwards, ${ }^{1}$ does not easily or simply describe this lesion. Along with the system described by Van Praagh and Van Praagh, ${ }^{4}$ it too depends on alphanumeric categorization. The subsets encountered in patients having common arterial trunk were recognized by both groups of investigators, but the alphanumeric systems devised to account for the variability differ markedly. The system devised by Van Praagh and Van Praagh ${ }^{4}$ did emphasize a key discriminating feature associated with surgical outcome, namely the presence of interruption of the aortic arch. In the cartoons used to illustrate this feature in the collaborative study by the Congenital Heart Surgeons' Society, ${ }^{2}$ however, no emphasis is placed on aortic hypoplasia, a feature revealed in all the specimens we studied that showed interruption of the aortic arch; such hypoplasia did receive appropriate emphasis in the cartoon provided by Van Praagh and Van Praagh. ${ }^{4}$

Because of these limitations, we see greater utility in a simplified system of categorization. Such a simplified approach was initially discussed by Calder and associates ${ }^{5}$ and then emphasized by Jacobs. ${ }^{6}$ This approach, based on the concept of either aortic or pulmonary dominance of the intrapericardial component of the common trunk, is simple. Moreover, it immediately provides the diagnostician and surgeon alike with the major feature of the particular lesion under review. The titles describe the nature of the pathways fed by the common trunk. All specimens we identified that had pulmonary dominance also had hypoplastic or interrupted aortic arches, so patients approached in this fashion are immediately characterized by the single most 


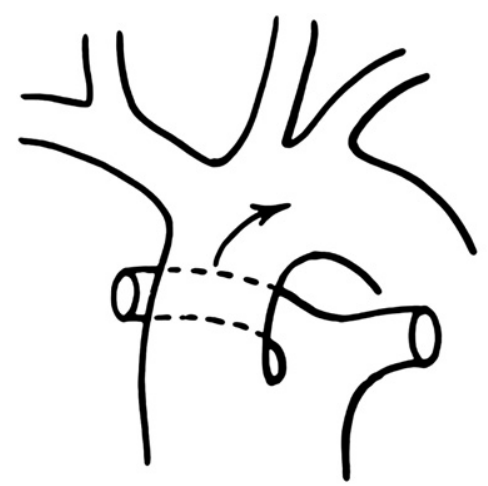

Figure 463 - Type 1

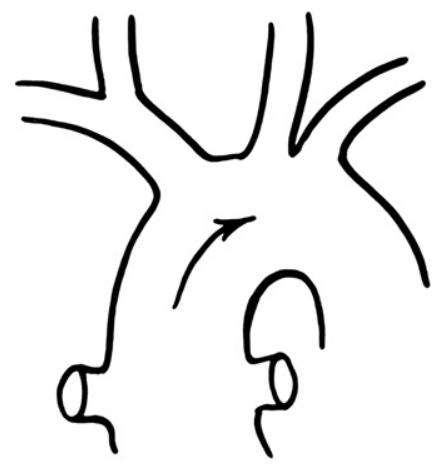

Figure 463 - Type 3

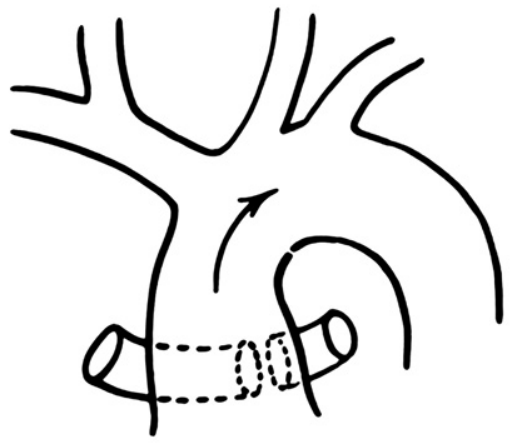

Figure 463 - Type 2

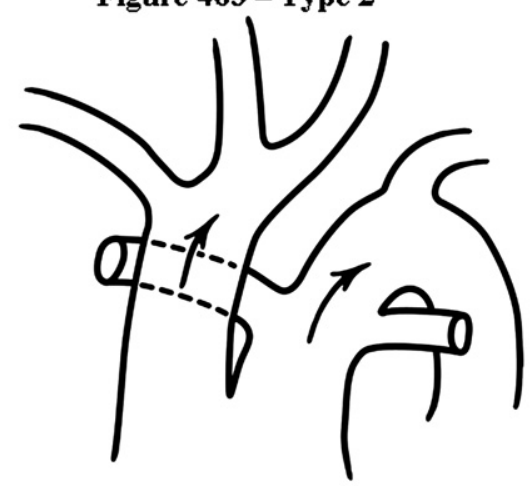

Figure 464e - Type 1, but also Type 3

FIGURE 8. In this cartoon, we have reproduced Figures $463 \mathrm{a}-\mathrm{c}$ and $464 \mathrm{e}$ from the original publication of Collett and Edwards, emphasizing the paradoxes existing in their classification. (Adapted with permission. ${ }^{1}$ )

important risk factor for outcomes. The patterns of origin of the pulmonary arteries in the patients with aortic dominance can then further be described as those with origin adjacent to one another from the common trunk, those with origins separate from the common trunk, or those with origin of one branch of the pulmonary artery from the common trunk and one supplied via a persistently patent arterial duct. In the material available for our review, the type 3 pattern initially identified by Collett and Edwards, ${ }^{1}$ in which the right and left pulmonary arteries took origin from the sides of the common trunk and with a significant distance between them, was found only in the setting of pulmonary dominance. The pattern of origin of the pulmonary arteries is an important feature for surgical planning and, in our opinion, should be noted. In this respect, we failed to find any patients or hearts with aortic dominance having the type 1 lesion proposed by Collett and Edwards ${ }^{1}$; this pattern was also depicted as type A1 in the scheme proposed by Van Praagh and Van Praagh. ${ }^{4}$ The rarity of patients with a discrete intrapericardial pulmonary trunk in the setting of aortic dominance has long been recognized, and numerous clinicians have commented on the need for a "type $1 \frac{1 / 2}{2}$ " when using the system devised by Collett and Edwards. ${ }^{1}$ Despite its rarity, there are enough reports to support the notion of a balanced pattern of branching of the common trunk, and we have therefore considered this possibility in our suggested categorization scheme.

Adachi and associates ${ }^{8}$ have recently emphasized the importance of pulmonary arterial origin from a truncal valvar sinus. Neither this relatively rare variant, nor the feature of crossed pulmonary arteries, ${ }^{9}$ is acknowledged in the popular alphanumeric systems of classification. In our clinical series, we encountered 1 patient with crossed pulmonary arteries in the setting of a pulmonary-dominant trunk in whom the unusual morphology had an important impact on the surgical procedure. The pattern of origin of the pulmonary arteries should be detailed in hierarchic fashion following the description of pulmonary or aortic dominance along with other important attributes, such as the presence and degree of truncal valve insufficiency, the origin of the common trunk relative to the right and left ventricles, and the morphology of the postero-inferior rim of the interventricular communication (Table 1).

In our autopsy archive we studied two hearts that had a common atrioventricular valve in the setting of common arterial trunk. Both of these hearts displayed pulmonary dominance of the common trunk. Because of the rarity of this lesion, further study and collaboration with other 
TABLE 1. Anatomic variation with common arterial trunk

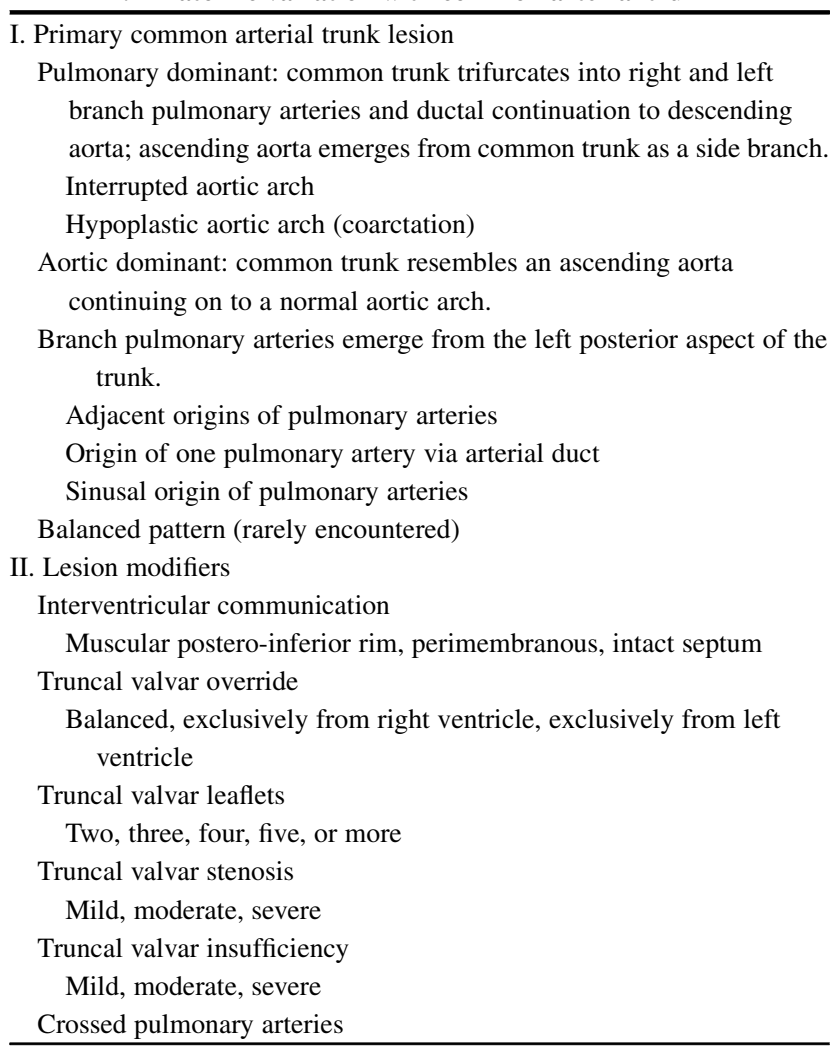

investigators will be required to determine whether there is an association between common atrioventricular valve and pulmonary-dominant common arterial trunk.

The Van Praagh subtype A3, ${ }^{4,5}$ in which one pulmonary artery is supplied by a persistently patent arterial duct, is found in the setting of aortic dominance. Although we found no autopsied specimens with this pattern, $10 \%$ of our surgical cohort possessed such origin of pulmonary arteries in the setting of aortic dominance, where one of the pulmonary arteries, most often the left, was fed extrapericardially by a patent arterial duct. It is the exception rather than the rule to find an arterial duct in a patient with a common arterial trunk. Thus, the duct is absent in the majority of cases of aortic dominance when the pulmonary arteries arise next to each other from the dorsal aspect of the common trunk despite having been illustrated in this setting by Collett and Edwards. ${ }^{1}$ We are aware of 1 heart in the archive of Children's Hospital of Pittsburgh that exhibits a patent arterial duct in the setting of balanced systemic and pulmonary pathways. In the setting of pulmonary dominance, of course, the arterial duct is an obligate part of the circulation, continuing extrapericardially to become the descending aorta.

Another feature of surgical significance is the morphology of the postero-inferior rim of the interventricular communication. Of the specimens at our disposal, one third had a perimembranous defect, whereas the remainder were muscular. In the original classification by Collett and Edwards, ${ }^{1}$ it was recognized that an interventricular communication was not an essential feature for diagnosis, even though all the cases they described had a ventricular septal defect. Cases having no ventricular septal defect have since been recognized either when there is univentricular origin of the trunk from the morphologic right ventricle, with closure of a pre-existing interventricular communication, or when leaflets of the truncal valve close on the crest of the muscular ventricular septum during ventricular diastole. ${ }^{10}$ These variants are sufficiently rare to warrant full discussion. They do not justify, in our opinion, the need for a complex alphanumeric system of classification.

We conclude that a classification that divides patients with common arterial trunk into those with either aortic or pulmonary dominance ${ }^{6}$ provides immediate anatomic description and is of great value in stratification of surgical risk. The single greatest risk factor for surgical mortality has been shown to be the presence of an interrupted or hypoplastic aortic arch. In our patients undergoing surgical repair, a clear difference was noted in mortality rates between these groups, although it did not reach statistical significance because of the small number of patients with pulmonary dominance, similar to other clinical series. Encouraging recent reports from single-institution series describe improving results in small cohorts of patients with the pulmonary-dominant form of common arterial trunk. ${ }^{11,12}$ In the largest multi-institutional collaborative study organized by the CHSS, which was designed specifically to investigate outcomes in patients with common arterial trunk and interruption of the aortic arch, ${ }^{2}$ less than half of the patients left the hospital alive after attempted surgical correction, and only $30 \%$ were alive after 10 years $^{2}$; these results are appreciably worse than the average survival rates in patients with common arterial trunk as documented in many large series. ${ }^{11-17}$ The scheme of aortic or pulmonary dominance, initially suggested by Calder and associates ${ }^{5}$ and championed by Jacobs, ${ }^{6}$ therefore, is simple and descriptive. It provides the optimal clinical categorization of patients with a common arterial trunk.

\section{References}

1. Collett RW, Edwards JE. Persistent truncus arteriosus: a classification according to anatomic types. Surg Clin North Am. 1949;29:1245-69.

2. Konstantinov IE, Karamlou T, Blackstone EH, Mosca RS, Lofland GK, Caldarone CA, et al. Truncus arteriosus associated with interrupted aortic arch in 50 neonates: a Congenital Heart Surgeons' Society study. Ann Thorac Surg. 2006;81:214-22.

3. Lacour-Gayet FG. Invited commentary: Truncus arteriosus associated with interrupted aortic arch in 50 neonates: a Congenital Heart Surgeons Society study. Ann Thorac Surg. 2006;81:222-3.

4. Van Praagh R, Van Praagh S. The anatomy of common aorticopulmonary trunk (truncus arteriosus communis) and its embryologic implications: a study of 57 necropsy cases. Am J Cardiol. 1965;16:406-25.

5. Calder L, Van Praagh R, Van Praagh S, Sears WP, Corwin R, Levy A, et al. Truncus arteriosus communis: clinical, angiocardiographic, and pathologic findings in 100 patients. Am Heart J. 1976;92:23-38. 
6. Jacobs ML. Congenital Heart Surgery Nomenclature and Database Project: Truncus Arteriosus. Ann Thorac Surg. 2000;69:S50-5.

7. Crupi G, Macartney FJ, Anderson RH. Persistent truncus arteriosus: a study of 66 autopsy cases with special reference to definition and morphogenesis. Am J Cardiol. 1977;40:569-78.

8. Adachi I, Uemura H, McCarthy KP, Seale A, Ho SY. Relationship between orifices of pulmonary and coronary arteries in common arterial trunk. Eur J Cardiothorac Surg. 2009;35:594-9.

9. Becker AE, Becker MJ, Edwards JE. Malposition of pulmonary arteries (crossed pulmonary arteries) in persistent truncus arteriosus. Am J Roentgenol Radium Ther Nucl Med. 1970;110:509-14.

10. Tsang VT, Kang N, Sullivan I, Marek J, Anderson RH. Ventriculoarterial septal defect with separate aortic and pulmonary valves but common ventriculoarterial junction. J Thorac Cardiovasc Surg. 2008;135:222-3.

11. Jahangiri M, Zurakowski D, Mayer JE, del Nido PJ, Jonas RA. Repair of the truncal valve and associated interrupted arch in neonates with truncus arteriosus. $J$ Thorac Cardiovasc Surg. 2000;119:508-14.
12. Bove EL, Lupinetti FM, Pridjian AK, Beekman RH, Callow LB, Snider AR, et al. Results of a policy of primary repair of truncus arteriosus in the neonate. $J$ Thorac Cardiovasc Surg. 1993;105:1057-65.

13. Thompson LD, McElhinney DB, Reddy M, Petrossian E, Silverman NH, Hanley FL. Neonatal repair of truncus arteriosus: continuing improvement in outcomes. Ann Thorac Surg. 2001;72:391-5.

14. Brown JW, Ruzmetov M, Okada Y, Palaniswamy V, Turrentine M. Truncus arteriosus repair: outcomes, risk factors, reoperation and management. Eur J Cardiothorac Surg. 2001;20:221-7.

15. Rajasinghe HA, McElhinney DB, Reddy VM, Mora BN, Hanley FL. Long-term follow-up of truncus arteriosus repaired in infancy: a twenty-year experience J Thorac Cardiovasc Surg. 1997;113:869-78.

16. Pearl JM, Laks H, Drinkwater D, Milgalter E, Charas OA, Giacobetti F, et al Repair of truncus arteriosus in infancy. Ann Thorac Surg. 1991;52:780-6.

17. Williams JM, de Leeuw M, Black MD, Freedom RM, Williams WG McCrindle B. Factors associated with outcomes of persistent truncus arteriosus. J Am Coll Cardiol. 1999;34:545-53. 